Technological University Dublin ARROW@TU Dublin

\title{
What Now?: Evaluating eLearning CPD Practice in Irish Third-Level Education
}

Roisin Donnelly

Technological University Dublin, roisin.donnelly@tudublin.ie

K. C. O'Rourke

Technological University Dublin, kevin.orourke@tudublin.ie

Follow this and additional works at: https://arrow.tudublin.ie/ltcart

Part of the Educational Assessment, Evaluation, and Research Commons

\section{Recommended Citation}

Donnelly, R., O'Rourke, K.: What Now?: Evaluating eLearning CPD Practice in Irish Third-Level Education. Journal of Further and Higher Education, Vol.31, 1, 2007,pp.31-40.

This Article is brought to you for free and open access by the Learning Teaching \& Assessment at ARROW@TU Dublin. It has been accepted for inclusion in Articles by an authorized administrator of ARROW@TU Dublin. For more information, please contact arrow.admin@tudublin.ie, aisling.coyne@tudublin.ie, gerard.connolly@tudublin.ie.

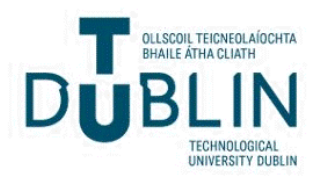


What now? Evaluating eLearning CPD Practice in Irish Third-Level Education

Roisin Donnelly and K.C. O'Rourke

Dublin Institute of Technology, Ireland

Phone: $0035314027886 / 7860$

Email: roisin.donnelly@dit.ie / kevin.orourke@dit.ie

Keywords: Third-level education; eLearning; Continuous Professional Development (CPD); teaching and learning. 


\begin{abstract}
The internet has made it impossible for higher education institutions to ignore technology in fulfilling their strategic mission and respond to the expectations of a diverse student body. In the Republic of Ireland, as elsewhere, the use of online technologies has become an increasingly important challenge in academic staff development, and on the surface, eLearning has been moderately successful in the teaching and learning environment. However, given the rapid rate of change in both technology and the increasing diversity in academic staff and students, to describe accurately the nature of eLearning for academic staff development is near impossible. There has been a constant balancing and rebalancing of the pedagogical and technical elements in teaching and learning online, and while much of the talk has been about pedagogy, many of the problems have been technical in nature. Furthermore, the issue of transferability of innovative approaches and developing the capacity to respond to innovation and rapid change remains a key area. This paper asks whether the technologies are being used in the best possible way. Calls for innovation within teaching and learning suggest eLearning, and as a result it is important to consider what influences staff engagement and participation in eLearning. In this way, a better understanding may emerge of the conceptions and practical approaches to their practice used by academic staff and eLearning developers.
\end{abstract}




\section{Introduction}

It has been widely accepted for some time that technology has the potential to enhance and transform the traditional learning experience, for students and teachers alike (Sloman 2001). In fact, information and communication technologies (ICTs) have acquired a sense of inevitability in education: initiatives to promote their use in teaching and learning are becoming the norm worldwide, and eLearning is part of almost every third-level institute's strategic vision. Informally, enthusiasm among academic staff for eLearning continues to grow, and where explicit institutional policies are lacking, pressure on lecturers to engage with new technologies is coming from students and from their own peers. And yet, it continues to be argued, the impact which technology is having on education is merely peripheral: teaching practices themselves remain largely unchanged (Zemsky and Massy 2004). In one sense this situation is not surprising: there is an ambiguity at several levels concerning the nature of the change which technology should bring to education, while the phenomenal rate of change in the actual technologies themselves do not necessarily fit with the traditional inertia of mainstream education practices. However, given the recognition of a diversity of learning styles and the desire to encourage active learning on the part of students themselves, the need for a better system for delivering education and training is paramount in the context of the move to a knowledge economy (Hameed et al. 2006). In this context, the demand for higher-education institutions to put eLearning initiatives and the accompanying academic staff training and development firmly on their agendas has resulted in a number of emergent issues. For example, many academic staff lack the online experience of the internet generation, and so do not feel as confident in an online environment as they do in a traditional classroom setting. In this context, the problem is a social rather than a pedagogic one, and lecturers may need to experience being an online student themselves in order to gain the necessary confidence to move to an online environment. Putting staff training online can be one response to this problem, but making more efficient use of lecturer time is more often the reason why the online environment is used. And such moves can lead to a negative rather than a positive experience of the online environment, in some cases leading academic staff to believe that buying in to this growing phenomenon means subscribing to their own eventual redundancy. As increasingly it is also becoming important not just to make such training more accessible, but explicitly designed to produce qualitatively improved 
pedagogy (Ham and Davey 2005: 263), it is important to ensure that the lecturer's first experience of an online environment is positive, one that will allow them to see the pedagogic possibilities at their disposal.

\section{The Irish context}

The third-level education system in the Republic of Ireland encompasses the university sector, the institutes of technology, the colleges of education, and private, independent colleges, and is thus quite broad in scope. The 20-plus institutions which fall within the first three groupings are autonomous and self governing, but substantially state funded. Surprisingly, until the 2006 strategic-innovation fund call, there has been little or no incentive for inter-institutional cooperation with regard to eLearning, and initiatives undertaken by each of these institutions have been at least formally independent of one another (see HEA 2006). This has resulted in a nationally diffuse pattern of eLearning CPD, with institutions adopting different approaches to implementation, and there is currently great diversity in institutional provision of professional development of eLearning in higher education. This may not altogether be a bad thing: informal meetings between institutions as well as contact through the Irish Learning Technology Association's (ILTA) annual Edtech conference means that institutions can share ideas and learn from each other's successes and mistakes. On the downside, however, the situation can lead to massive duplication of effort across the institutions, as well as poor economies of scale, with each institution using a limited amount of funds to achieve what is essentially the same goal. Moreover, responsibility for eLearning development lies with groups as varied as library staff, IT staff, staff development officers, learning and teaching support staff or, in some cases, with learning technology staff specially employed for the purpose. Each such group will usually have a pre-existing approach to training which more likely than not will be mapped onto their eLearning development efforts.

This situation has, to a greater or lesser extent, mirrored what has happened in academic staff development in the UK where, as Shephard (2004) has suggested, there is a dichotomy between the entities of academic support services and professional development. The technological-pedagogical division of eLearning echoes this dichotomy, and often finds its way into the perceptions of academic staff 
who tend initially to regard an introduction to eLearning as a course in ITCs rather than an effort to change or improve their teaching abilities. Perhaps to counter this, Segrave et al. (2005) argue for a strategic, systems-based approach to academic professional development. Such an approach requires a clear view of the key areas of potential and enduring teaching and learning benefits which can be realised from online developments. These include an understanding of the changing role of the academic, identification of the desired professional capacities to educate online, and the implementation of a number of coordinated initiatives to develop these professional capacities in order to engage constructively with the learning and technological opportunities. Just who should take responsibility for this may differ in practice, but an appreciation of the lecturer's perception of where the training originates is important. Where 'traditional' learning and teaching specialists do not take responsibility for eLearning may bring with it the suggestion that eLearning is not a pedagogical innovation, a suggestion reinforced by the fact that implementation policies commonly reflect the procedures of the IT department. In such situations, collaboration between learning and teaching specialists and the relevant eLearning implementers would seem a necessary first step to counter such perceptions. In fact, the complementary and overlapping relationship between the two can be capitalised upon to generate effective eLearning CPD which embodies sound pedagogic practice, resulting in the creation and construction of learning activities which profit the student.

Most, if not all, the UK university sector are utilising technology to develop what is considered to be eLearning (O’Neill et al. 2004); many of these implementations are costly, but superficial in terms of learner engagement and activity. However, as Ash and Bacsich (2002) suggest, there is no single accepted methodology to explain how a move to eLearning could benefit organisations in both the short and long term. In fact, other than demonstrating that technology is being used, institutions themselves often seem uncertain how to measure whether their investment is paying off. Quantity of materials available online frequently if not always takes precedence over the quality of what is being made available, and success is frequently measured in terms of volume of use of particular software products and virtual learning environments (VLEs). The result for many students can be continuous "reading up" (from the screen) as well as "reading down" (when they choose to print the material), ultimately 
encouraging shallow rather than deep learning. Our experience at the Dublin Institute of Technology (DIT) suggests to us that this situation is being paralleled here: VLEs provide a content repository but, in many cases, limited active learner participation. eLearning products are often lauded on the basis of their constructivist approach to learning, but in reality sustained inter-student contact and discussion can be difficult. There is a qualitative difference between 'teaching online' and merely 'putting a course online'; a central feature of academic staff development involves conveying the difference between using technology as a delivery mechanism and using it as a communications medium. In the synchronous and distributed VLE, it is claimed, you can interact more thoughtfully and more often to more people. Studies report the benefits of online communication in extending classroom discussions, improving interaction between student and teacher (Collins 1998) and increasing timemanagement ability, self-directive behaviour, self-confidence and self-discipline (McFerrin 1999). Yet a common problem for academic staff is that they find asynchronous facilities a hindrance rather than a help to learning. Students too are reluctant to use them in a formal academic setting for a number of reasons, in contrast to the growing popularity of social networking sites such as those provided by Bebo and Facebook: asynchronous interaction can inhibit spontaneous development of ideas; in collaborative projects, a student may also make significant progress down the 'wrong path' through research or practice before his or her group-mates can correct an improper understanding of that student's role in the group for that particular assignment; in addition, asynchronous interaction inhibits the quick allocation of tasks and formation of schedules to get problem-solving activities completed (Garrison and Anderson 2003). Furthermore as traditional face-to-face group dynamics can still tend to be the benchmark by which the value of the learningteaching experience is judged, online pedagogies are frequently valued by academic staff only in proportion to how well they seem to reproduce or simulate an equivalent face-to-face experience. Where this fails (as it often does) lecturers may revert to using the VLE as a method for distributing lecture notes, or may simply abandon using it altogether.

\section{Emergent issues in supporting eLearning CPD}

Considering all these factors, it seems fair to conclude that any successful CPD eLearning strategy should involve facilitating a fundamental change in perception for 
lecturers regarding both the nature of education itself and their role within it.

However, given the range of models available and the immaturity of eLearning itself, it is difficult to demonstrate which initiative is working and which is not, and much published analysis appears to be poorly applicable to wider circumstances. Surry and Land (2000) reviewed generic strategies for motivating academic staff in the USA, with a particular emphasis on reward and recognition processes. Hanson (2003) has conducted a study on strategic implementation of eLearning in Australian universities. Shephard (2004) believes that irrespective of the availability of academic support services and professional development services, the limiting factor for teachers is their ability to commit time to the innovation. Surveys, both formal and informal, among staff at our institution have thrown up similar concerns. Moreover, of those DIT staff who have expressed a wish to engage with eLearning, on average less than half of those who attend an initial day-long introductory session proceed immediately to employ it as part of their practice, citing time constraints as the main inhibiting factor. (Other factors cited include difficulty in using the software, fears that the use of eLearning will inhibit attendance at regular classes, and even fears that the technology will be used as a surveillance device.) McConnell (2006: 25) argues that a major motivating factor in the uptake of eLearning in organisations is 'the professional development of trainers, course developers and teachers in the new form of learning provision'. This echoes the sentiments of other researchers in the field (see Segrave et al. 2005), and forms the core of many institutions' eLearning strategies. However, clear problems have been identified with the progress of the use of ICTs to support learning. Conole (2002: 14) for example, suggests that in the UK the 'take-up of ICT in teaching is still fairly low' and points to the lack of ICT skills of staff and students, along with resistance to change, as two of several contributory factors. Although since that time, increasing numbers of learners are working online, few lecturers have themselves actually learned this way, although it is generally accepted that one of the best ways to learn how to be an effective online tutor is to undertake an online course and experience what it is like from a student perspective (Salmon 2000; Kempe 2001; Ambrose 2001).

Online teaching is not a skill that many lecturers have acquired vicariously through observing teachers whilst they themselves were learning. In fact, most eLearning training and development provision appears to be designed in the form of short 
courses and delivered in traditional face-to-face mode. One argument against such forms of training is that they do not foster participative learning or critical, analytical thinking. The oft-quoted statement in the literature is that the emphasis is often on the technology rather than on how the technology can facilitate learning. In our experience, this can actually be a direct response to expectations of lecturing staff, who want to learn how to use software packages to supplement their existing practices rather than to be instructed on how to fundamentally change those practices. And a large body of research findings reveal that teachers' beliefs are an important variable to consider when designing faculty development initiatives (Clement et al. 2003). So to imbue a thorough understanding of approaches to design that sustain eLearning in ways that lead to quality learning processes and outcomes is very important. The nature of academic staff's varied work responsibilities is complex, with demands on their time (ranging from lesson preparation, student support and research, to staff meetings, curriculum development etc.) pulling them in many directions. They need to be provided with streamlined learning experiences which deliver essential topics and learning materials in readily accessible formats (Donnelly and O'Farrell 2006). Segrave et al. (2005) have argued that a central challenge here is to create and sustain quality eLearning environments of enduring value for teachers and learners; as part of this, they argue that strategic academic professional development must come to the fore.

And so it is clear that those lecturers involved in facilitating eLearning require assistance in making the paradigm shift from 'conventional' teaching and learning to teaching and learning in 'virtual', or networked, environments. The availability of online learning resources arguably now makes it possible to provide seamless, eLearning environments that can be used to support learning in any part of the institution, anywhere across the globe. However, such opportunities for provision of CPD pose significant questions about the design and delivery of eLearning, and about the development of understanding and skills required in offering courses in this way. Indeed, McConnell (2006) believes that the education and training sectors are being forced to make decisions about implementation while their knowledge and understanding of the learning potential of the new learning technologies is still emerging. Meanwhile, the absence of formal recognition of the practical implications of a changing learning paradigm and its incumbent structures means that lecturers' 
concerns about the introduction of eLearning and its effect on their working conditions and on the learning environment generally are beginning to find formal expression through other means (see, for example, TUI 2006).

\section{A strategy for eLearning CPD}

At DIT, a specialist Learning Technology Team of five was established in 2002 to implement eLearning, working initially for three years to complement the existing Learning and Teaching Centre. A training programme for the some 1,500 academic staff across the institute was devised collaboratively and based on a number of ideas. Ultimately it aims to encourage lecturers beyond thinking about the technicalities of how to use software and instead to develop a clear pedagogical rationale for their online teaching, rooted in a personal philosophy of teaching and learning. It is designed to convey to academic staff that teaching online is not merely a set of instructional practices that exists independently of either its delivery mode or its ongoing interpersonal context. Valsamidis (2006) argues that focusing on the delivery of material instead of on the much more crucial interaction of the material with the learner, mediated by a tutor through a rich channel of communication, results in a mismatch in how some CPD is designed. In line with this thinking, the second goal is to optimise the effective use of ICT as vehicles for ongoing student-to-student interaction during formal course delivery. Local design and implementation of eLearning CPD was chosen, as this can expect to result in higher levels of perceived relevance to teachers and have greater impact on the development of teaching skills than would have been the case had the training been centrally designed and delivered (Lave and Wenger 1991; Brew 1995; Webb 1996).

Different formats for workshops were tried before finally settling on an initial full-day introductory session, since a seeking a commitment to a full day signifies from the outset the importance of this first step towards a new learning paradigm being undertaken by lecturers; it also allows participants the time to engage critically and collectively with the ideas being exchanged. The sessions themselves consist of three parts under the headings 'The student experience', 'eLearning before eTeaching', and 'The lecturer experience'. In the first hour, participants are given the opportunity to communicate in the virtual learning environment using both synchronous and asynchronous discussion, before completing a short online module and finishing with a 
multiple-choice question assessment. For a high proportion of participants, this is a first-time direct experience of an eLearning environment, and the session is designed to put them at ease in order to see beyond the technology. This is usually followed by a half an hour in which one of their peers who is already actively using eLearning with students presents his or her experiences and answers questions (which always includes at least one about the amount of time they have spent developing their online presence). The second session is intended to develop the participants' understanding in the area of pedagogic design. Participants are encouraged to capture instances of effective practice, using templates and examples provided and establish principles of effective 'design for learning'. They are encouraged to share ideas for embedding the materials in their own contexts of activity. They do not involve any skills training and it is not until the final hour of the day that the practicalities of uploading materials and using the software are addressed, and while assessment-creation and communication tools are demonstrated, participants are invited to attend separate sessions (ranging in length from an hour to another day-long course) to engage with the issues.

An important consideration in all strategies is the recognition of the importance of evaluation and reporting of eLearning innovations that either may turn out to be successful, or have experienced problems for a variety of reasons. Anonymous formal feedback from participants is actively solicited, and workshops are subsequently changed in response to comments received. (Many of the initial views expressed surprise at the amount of work which a move to eLearning demands.) Other workshops were subsequently devised in response, including sessions on assessment, communicating and emoderating, administration and even one on eLearning for nonacademic staff. Following attendance at one of these workshops, individuals had the opportunity to work directly with an instructional designer in the development of their online presence. In response to those whose workload made it impossible for them to attend any such session, a week-long eLearning Summer School was devised to run at the end of the academic year in which all these aspects of eLearning were covered using a mixture of hands-on workshops and reflective discussions. Reaction to this now annual event has been enormously positive, and it attracts an annual attendance of 40 to 50 academic staff from within DIT, from other Irish academic institutions and from abroad. 
However, attendance at any of these workshops or events is neither compulsory for academic staff nor formally recognised by the departments, schools and faculties within the institute. As it is important to incorporate capacity development in formal courses on higher education (Segrave et al. 2005), a postgraduate programme in thirdlevel learning and teaching was developed in 2001, and has 40 graduates today. It includes a popular 'Designing eLearning' module, which carries ten ECTS (European Credit Transfer and Accumulation System) credits. Academic staff who have participated in the Institute's Postgraduate Certificate in Third Level Learning and Teaching, and who for that programme had produced an individual personal philosophy of teaching, have in general displayed a much better awareness of how to adapt eLearning into their practice. A more recent initiative in accredited course development is an MSc in Applied eLearning (60 ECTS credits), which aims to provide participants with a comprehensive grounding in the use of eLearning, including the required knowledge and skills to be practitioners and consultants in the field of eLearning in a tertiary education or industry context. Other Irish third-level institutions have similarly begun to offer postgraduate programmes in eLearning.

\section{Conclusion: implications for future eLearning CPD}

Certainly, as it is currently being used on campus, eLearning is not delivering the wide benefits to education which were expected: the anticipated sweeping impact of the new technologies on restructuring the learning and teaching practices at universities (and with it their high-profit prospects) have not materialised. In further education, whilst staff skills and access to ICT, colleges' ability to access and produce electronic resources, and the extent to which eLearning is deployed have all moved steadily forward, blended learning activity has become more widespread (Becta 2005). Yet the results of generic explorations have yet to reveal a consistent and reliable body of knowledge indicating that improved learning and cost savings are an outcome of the use of eLearning. Perhaps the only aspect that research has shown, with consistency, is that these benefits are not easily achieved in the eLearning classroom. Moreover, now that eLearning has reached a critical mass in terms of adoption, expressions of lack of confidence and cynicism are also emerging. Research has identified mainstream uncertainties emerging from the increasing use of eLearning, including the deprofessionalisation of academic staff, erosion of academic 
freedom and agency, commercialisation of teaching, lack of face-time between students and faculty, technocentric models being prioritised over campus culture, devaluing of oral discourse/discussion practices, centralisation of decision making and service provision, increased technological and pedagogical uniformity, and concern about the growing digital divide and downloading of costs to students (Kanuka 2006).

It is interesting to note that many of these concerns are arising from experienced educational technologists who have been researching eLearning for the past twenty years or more. A premise for future research in the area is that since eLearning has been applied to education for more than two decades, and extensively within the last decade, it now seems a possibility that it will not in itself transform education. A significant barrier to this has been identified as teachers' refusal to change how they are teaching and/or resistance to use technologies.

In fact, by facilitating distribution of course materials and with this a consequent diminishing in student attendance at traditional lectures, technology may well be serving to narrow the educational experience rather than broaden it. In this context, the need to encourage engagement with eLearning CPD opportunities has never been greater, enabling participants to experience, discuss and reflect on pedagogical issues related to teaching and learning online, thereby enabling them to relate their understanding and practice to appropriate educational principles and key institutional policies. The suite of programmes on offer to academic staff needs to be integrated with various levels and types of expert and peer practitioner support at faculty and institutional levels, provided both through online and face-to-face encounters. In this way, translating their CPD experiences into their own environments could become easier, allowing them to work effectively within an eLearning environment in the future.

When utilising emerging technologies to support the continuing professional development of academic staff, it is essential to regularly reassess the pedagogical methods employed to do so, in order to ensure the best experience for the teacher. It is important that training and development in the use of these learning technologies takes into account the specific individual context in which it is being implemented, 
paying attention to the institutional, cultural and pedagogical imperatives of that context.

So, while eLearning has not delivered on many the promises made by technologists at the turn of the millennium, it still does have great potential to widen access, cost effectively, under certain circumstances. Educational developers provide practical knowledge, develop skills and attributes, introduce new concepts and methods, and inspire innovation within the academic community. We concur with Maddocks (2006) who believes they have a major contribution to make in supporting eLearning within higher education institutions in the future.

4016 words 


\section{References}

Ambrose, L. (2001) Learning Online Facilitation Online, Moving Online Conference II, Gold Coast, Australia. Available online at: http://pre2005.flexiblelearning.net.au/leaders/fl_leaders/fll00/lyn_ambrose.htm (accessed 21 September 2006).

Ash, C. \& Bacsich, P. (2002) The Costs of Networked Learning, in: C. Steeples \& C. Jones (Eds) Networked Learning: Perspectives and Issues (London, Springer Verlag).

Becta (2005) ICT and eLearning in Further Education: The Challenge of Change. Available online at:

http://ferl.becta.org.uk/content_files/ferl/pages/surveys/ICTandelearning2005/ICT_in _FE_report.pdf (accessed 21 September 2006).

Brew, A. (Ed) (1995) Directions in Staff Development (Bristol, Society for Research into Higher Education, Open University Press).

Clement, M., Clarebout, G. \& Elen, J. (2003) University Teachers' Beliefs About Goals and Characteristics of Good Instruction, International Journal for Academic Development, 8(12), 159-163.

Collins, M. (1998) The Use of Email and Electronic Bulletin Boards in College-level Biology, Journal of Computers in Mathematics and Science Teaching, 17(1), 75-94.

Conole, G.C. (2002) E-Learning and future perspectives. Invited talk at Northumbria conference, 2nd July 2002.

Donnelly, R. \& O'Farrell, C. (2006) Blended E-Learning for Continuous Professional Development of Academic Staff, in J. O'Donoghue (Ed.) Technology Supported Learning and Teaching: A Staff Perspective (Hershey PA, Information Science Publishing).

Garrison, D. \& Anderson, T. (2003) E-Learning in the 21st Century (London, Routledge Falmer). 
Ham, V. \& Davey, R. (2005) Our First Time: Two Higher Education Tutors Reflect on Becoming a 'Virtual Teacher', Innovations in Education and Teaching International, 42(3), 257-264.

Hameed, C., Hameed, K., \& Clements, M. (2006) 'E'learning: Through the Looking Glass. Abstract from The Higher Education Academy Information and Computer Sciences $7^{\text {th }}$ Annual Conference, Trinity College Dublin, 29-31 August.

Hanson, J. (2003) Staff development for ICT and e-learning: skills or pedagogy? in Keeping up with our neighbours: e-learning in Australian higher education LTSN/Association for Learning Technology Conference workshop.

Higher Education Authority (HEA) (2006) Strategic Innovation Fund Call for Proposals. Available online at http://www.hea.ie (accessed 21 September 2006).

Kanuka, H. (2006) Has eLearning Revolutionized Education? Embassy Report, February 22nd, 2006. Available online at:

http://www.embassymag.ca/html/index.php?display=story\&full_path=/2006/february/ 22/elearning/ (accessed 8 September 2006).

Kempe, A. (2001) Putting the Teacher Online. Paper presented at NET*Working 2001 Conference. Available online at:

http://flexiblelearning.net.au/nw2001/01_attending/papers/4_6Kempe.doc (accessed 21 September 2006).

Lave, J. \& Wenger, E. (1991) Situated Learning: Legitimate Peripheral Participation (Cambridge, Cambridge University Press).

Maddocks, A. (2006) Promoting More Effective Use of eLearning within the Staff and Educational Development Community. Conference Paper Presented at ALT-C, the $13^{\text {th }}$ International Conference, Heriot-Watt University, 5-7 September. 
McConnell, D. (2006) E-Learning Groups and Communities (Maidenhead, SRHE and Open University Press).

McFerrin, K.M. (1999) Incidental Learning in a Higher Education Asynchronous

Online Distance Course, in: J.D. Price, J. Willis, M. Jost, \& S. Boger-Mehall (Eds)

SITE 99: Proceedings of the Society for Information Technology \& Teacher education International Conference, San Antonio TX, 28 Feb - 4 Mar (Charlotteville VA, Association for the Advancement of Computers in Education (AACE)), 14181423.

O’Neill, K., Singh, G. \& O’Donoghue, J. (2004) Implementing eLearning Programmes for Higher Education: A Review of the Literature, Journal of Information Technology Education, 3, 314-320.

Salmon, G. (2000) E-Moderating: The Key to Teaching and Learning Online (London, Kogan Page).

Segrave, S. Holt, D. \& Farmer, J. (2005) The Power of the $6^{\text {three }}$ Model for Enhancing Academic Teachers' Capabilities for Effective Online Teaching and Learning: Benefits, Initiatives and Future Directions, Australasian Journal of Educational Technology, 21(1), 118-135.

Shephard, K. (2004) The Role of Educational Developers in the Expansion of Educational Technology, International Journal for Academic Development, 9(1), 67 83.

Sloman, M. (2001) The e-Learning Revolution: From Proposition to Action (London, Chartered Institute of Personnel and Development).

Surry, D.W. and Land, S.L. (2000) Strategies for motivating higher education faculty to use technology. Innovations in Education and Training International, 37(2), 1-9. 
Teachers Union of Ireland (TUI) (2006) Congress Motions: Resolutions Carried, Congress 2006, TUI News, 28(4), 21-22 (D60 and D61). Available online at http://www.tui.ie (accessed 21 September 2006).

Valsamidis, T. (2006) Where is the " $e$ " in elearning? Abstract from The Higher Education Academy Information and Computer Sciences $7^{\text {th }}$ Annual Conference, Trinity College Dublin, 29-31 August.

Webb, G. (1996) Understanding Staff Development. (Milton Keynes, The Society for Research into Higher Education and the OU Press).

Zemsky, R. and Massy, W.F. (2004) Thwarted Innovation: What happened to eLearning and why (West Chester, PA: The Learning Alliance at the University of Pennsylvania). 